\title{
Monsoon rainfall forcing on the silicate weathering in the Yellow River basin during the last $400 \mathrm{ka}$
}

\section{DEBO ZHAO AND SHIMING WAN}

Institute of Oceanology, Chinese Academy of Sciences

Presenting Author: zhaodebo@qdio.ac.cn

The chemical weathering of silicate rocks is a critical sink for atmospheric $\mathrm{CO}_{2}$ in the long-term carbon cycle. Because of the dependence on temperature and humidity, chemical weathering of exposed silicate minerals was suggested to have been suppressed/promoted by cooler/warmer and drier/wetter conditions during glacial/interglacial periods in late Quaternary. Most previous studies have revealed that silicate weathering only showed coherency with the global benthic $\delta^{18} \mathrm{O}$, suggesting its temperature, rather than rainfall control during glacialinterglacial cycles. This results the impact of continental weathering on $\mathrm{CO}_{2}$ fluxes has generally been considered minor. Here we provide a sediment record from IODP Site U1429 in the East China Sea spanning the last $400 \mathrm{ka}$. Provenance tracing based on the $\mathrm{Nd}$ isotope and trace elements from clay minerals in the sediments suggests that clay-sized sediments in the study site were mainly from the Yellow River. Silicate weathering proxies including $\mathrm{K} / \mathrm{Al}$ and $\mathrm{Mg} / \mathrm{Al}$ from clay-sized sediments show obvious precession cycle, and indicate that silicate weathering in the Yellow River drainage basin was mainly controlled by the East Asian summer monsoon rainfall change. Such precessionscale variation of silicate weathering in the monsoon region during glacial-interglacial cycles should consume a considerable amount of atmospheric $\mathrm{CO}_{2}$ and thus have potentially enhanced its drawdown during cold stages of the Quaternary. This in turn would have caused an intensification of glacial cycles. 